\title{
Polycystic ovary syndrome: implications of metabolic dysfunction
}

\section{Síndrome dos ovários policísticos: implicações da disfunção metabólica}

\author{
Márcio Augusto Pinto de Ávila, tCBC - RJ1; Ricardo Vasconcellos Bruno, TCBC - RJ2; Fábio Cuiabano Barbosa ${ }^{3}$; Felipe Cupertino \\ de Andrade ${ }^{4}$; Adriana Cardoso de Oliveira e Silva ${ }^{5}$; Antonio Egídio Nardi ${ }^{6}$
}

A B S T R A C T

\begin{abstract}
Objective: To determine the prevalence of metabolic syndrome (MS) and its clinical interrelations in polycystic ovary syndrome (PCOS). Methods: This was a cross-sectional, prospective study with 100 patients with diagnosed PCOS based on the consensus of Rotterdam (2003). We investigated the interrelationships of MS, with intrinsic PCOS data. Dermatological profile was analyzed, in addition to acanthosis nigricans (AN) in the presence of hirsutism and acne. The use of HOMA-IR (homeostatic model assessment of insulin resistance) aimed at the correlation with MS in order to establish the metabolic dysfunction with the state of insulin resistance. Results: The mean and standard deviations corresponding figures for age, body mass index and waist circumference were, respectively, $25.72( \pm 4.87), 30.63( \pm 9.31)$ and $92.09( \pm 18.73)$. The prevalence of MS was $36 \%$ and significantly correlated with BMI, AN, and in $51 \%$ of patients the state of insulin resistance (HOMA-IR). Regarding skin profile, only AN significant correlation with MS. Conclusion: We propose the routine inspection of metabolic components related to severe PCOS. These parameters configure the cardiovascular risk and such conduct is of undoubted importance to public health.
\end{abstract}

Key words: Polycystic ovary syndrome. Metabolism. Acanthosis nigricans. Insulin resistance. Prevalence.

\section{INTRODUCTION}

avish in interpretations, the 60, (XX Century) coined the term "Polycystic Ovary Syndrome", applied to functional ovarian hyperandrogenism, incident in varying degree, both in the expression of cutaneous signs and in the levels of circulating androgens, influenced by the increase in insulin consecutive to glandular interrelationships that provide, from adolescence, endocrine fullness.

However, recent investigation procedures transcend the purely endocrine assumptions, so that they oppose the classic text, the description of Stein and Leventhal 1 , tied to the phenotypic heterogeneity that, from a clinical point of view, comprise, more often, menstrual irregularity, hirsutism and infertility. In the light of current knowledge, the polycystic ovary syndrome (PCOS) is extended and comprises an enormous field of intricate metabolic disturbances inherent to the broad concept of vascular disease.

Part of the diagnostic constitution, the development of dermal manifestations associated with PCOS is not exempt from questioning. Hormonal and metabolic factors interact in such a way that changes in homeostasis put themselves in line with the worsening of the aspects that comprise the dermatologic profile of PCOS. The important role of androgens, in spite of positive and negative associations with the skin condition, takes into account, the possibility of not detecting hyperandrogenemia.

Significant evidence points to the increased risk of type 2 diabetes in patients with $\mathrm{PCOS}^{2}$, whereas there is alleged cardiovascular involvement in long- term ${ }^{3.4}$. However, the prognosis is in summary expressed through the combination of risk factors that make up the concept of metabolic syndrome (MS), relevant to the careful assessment of PCOS, which is accompanied, as a rule, by the state of insulin resistance (IR) along with compensatory hyperinsulinemia. It is concluded that the timely recognition of patients likely to develop hypertension, altered glucose metabolism and atherosclerosis, among other parameters judged by greater severity, provides undeniable benefit in relation to the public health sphere.

This work aimed to establish the prevalence of MS and its clinical interrelationships with PCOS. Simultaneously, we tried to estimate the possible connection of MS with the adverse homeostatic condition of insulin resistance, obesity and the presence of acanthosis nigricans (AN), to reflect the impact attributed to PCOS as an early marker of cardiovascular disease.

1. Department of Obstetrics and Gynecology, Federal University of Rio de Janeiro - UFRJ; 2. Institute of Gynecology, UFRJ; 3. Fellow Mount Sinai New York Hospital, New York; 4. Course in Dermatology, HUCFF-UFRJ; 5. Department of Psychiatry, Fluminense Federal University; 6. Department of Psychiatry - UFRJ. 


\section{METHODS}

One hundred patients affected by PCOS were selected in the Endocrine Gynecology Division of the Institute of Gynecology, Federal University of Rio de Janeiro (UFRJ).They were diagnosed by the Rotterdam criteria ${ }^{5}$ and assisted in the period between April 2002 and May 2009, in a cross-sectional, prospective study. The clustering of cardiovascular risk factors entails the classification of MS according to the proposition of Grundy et al. ${ }^{6}$. The diagnosis is confirmed by the presence of at least three altered components including Type 2 diabetes. The description of the cutaneous examination, besides $\mathrm{AN}^{7}$, searched for hirsutism (score> 8) according to the modified criteria of Ferriman and Gallwey, Hatch et al. ${ }^{8}$, and for acne ${ }^{9}$. We defined amenorrhea as the absence of vaginal bleeding for more than six months and oligomenorrhea as menstrual intervals longer than 45 days. Irregular ovulation was detected between the 20th and the 24th days of the cycle by progesterone levels $(<3 \mathrm{ng} / \mathrm{ml})$ after two consecutive cycles. All patients with amenorrhea underwent ultrasonography, and when they had less than $5 \mathrm{~mm}$ endometrial thickening they were subjected to hormonal dosages.

The clinical features evaluated were: age e" 16 years, weight $(\mathrm{kg})$, height $(\mathrm{m})$, body mass index (BMI) and measurement $(\mathrm{cm})$ of waist circumference (WC) with nonelastic measure tape disposed between the bottom of the last rib and the superior border of the iliac crest, with the patient in upright position during expiration. The weight groups according to BMI were thus defined: Normal (18.5 $\left.\mathrm{kg} / \mathrm{m}^{2}-24.9 \mathrm{~kg} / \mathrm{m}^{2}\right)$, Overweight $\left(25 \mathrm{Kg} / \mathrm{m}^{2}-30 \mathrm{Kg} / \mathrm{m}^{2}\right)$ and obesity $\left(>30 \mathrm{Kg} / \mathrm{m}^{2}\right)$. Blood pressure $(\mathrm{mmHg})$ was measured in the right arm with the patient seated, after about ten minutes of rest.

Hormonal metabolic estimates, as well as transvaginal ultrasound (image interpreted according to the precepts of Balen et al. ${ }^{10}$ ), were held between the third and seventh days of the menstrual cycle and blood collection (until $9 \mathrm{am}$ ) was preceded by fasting (12h). The HOMA-IR (homeostatic model assessment of insulin resistance) showed insulin sensitivity, with a cutoff e" $1.8^{11}$ and measuring by HOMA Calculator ${ }^{12}$. The metabolic parameters were completed by serum fasting glucose, glycated hemoglobin and oral glucose tolerance test (OGTT). To evaluate fasting glucose, high sugar intolerance and to attest to the diabetic state, the criteria extracted from published reference ${ }^{13}$ were used. Endocrine-metabolic research was complemented with the addition of hormonal parameters such as: FSH (follicle stimulating hormone), LH (luteinizing hormone), 17-hydroxyprogesterone, estradiol, prolactin, progesterone, cortisol, thyroid stimulating hormone (TSH) and insulin, whose levels have served to exclude other causes similar to the PCOS, as well as the estimation of testosterone, total and free, to complement the biochemical elements that lead to the diagnosis of
PCOS. With regard to hormones, the process of ACS: 180 D Ciba-Corning Diagnostics chemiluminescence was used; insulin was measured by radioimmunoassay with gamma counter, and as for biochemistry, the appliances Selectraone or Express-plus were used.

The exclusion criterion concerned endocrine diseases and related conditions likely to cause direct or indirect disturbances of the menstrual cycle, which provide analogy or bond with PCOS. The restriction extended to the use of hormones 60 days prior to selection of patients. An identical precept was applied to medication usage, such as the calcium simvastatin and metformin, and substances that interfere with lipid metabolism. An anomalous LH / FSH ratio was not considered diagnosis principle of PCOS. We also excluded patients with a history of antibiotic treatment for more than one week in the last six months, habitual smoking and alcohol consumption, and drug addictions in general. Proven vascular (coronary or renal) disease was also an exclusion criterion.

Concerning statistical procedures, we took into account the gross amount, percentage, mean and standard deviation with the maximum and minimum values found (for continuous variables). We used the chi-square $(\div 2)$ test with the descriptive data for categorical variables. For the difference between the means of continuous variables (for different categories) we used the Student t test. The criterion adopted for the coefficient of significance $(p<0.05)$ corroborated the analysis.

The protocol was approved by the Ethics Committee in Research of the Institutes of Gynecology and Psychiatry at the Federal University of Rio de Janeiro (UFRJ,) under number 23079. All patients were presented to, and signed, The Informed Consent form, according to Resolution 196/96 of the National Health Council.

\section{RESULTS}

Analysis of clinical data (Table 1) shows the patients' average around 25 years. While BMI and AC were predominant altered, normal weight comprised $35.6 \%$ of the measurements, and $\mathrm{AC}$ less than $80 \mathrm{~cm}$ was present in $37.5 \%$ of patients.

Disorders of the menstrual cycle, as exposed, are common in PCOS. Thus, amenorrhea (63\%) exceeded significantly oligomenorrhea (28\%). MS affected $36 \%$ of patients, with a significant expression of only three altered components of the classification. Besides NA, cutaneous manifestations were restricted hirsutism and acne. The incidence of AN was greater than 95\%, predominantly in the neck (posterior and lateral aspects), alone or in combination with other areas. AN rarely overcomes acne, even in small proportion, despite the strong presence of hirsutism, the usual predominant cutaneous manifestations of PCOS, in theory only surpassed in the clinical setting by oligomenorrhea. The incidences of hirsutism, acne and 
AN were $72 \%, 49 \%, 53 \%$, respectively. Statistical analysis showed no significant difference in the average age of groups with or without MS (Table 2). However, involvement by MS showed significant correlation with BMI, overpowered by the constitution of overweight and obesity, with AN, and in $51 \%$ of patients, with insulin resistance (HOMA-IR). Moreover, the prevalence of cutaneous manifestations confer significance exclusively to AN combined with MS. The significant correlation restricted to AN is due to the predictable bond of the condition with IR and obesity. Despite more prevalent, amenorrhea did not display significant correlation with MS, similar to oligomenorrhea and normal menstrual cycle.

There was absence of type 2 diabetes with concomitant glucose intolerance in eight patients, which is attributed, at least in part, to the average age of the patients. However, regardless of the age factor, these findings demand routine inspection of the factors related to the cardiovascular risk supposed to increase with the metabolic disorder.

\section{DISCUSSION}

Insulin resistance seems to be the common factor responsible for the development or acceleration of many disorders that no rarely act together and for which it is proposed a variety of etiological mechanisms. In 1988, Reaven formalized the implications of IR along with glucose intolerance, lipid disorders and hypertension ${ }^{14}$. Such combinations maintain correspondence of cause and effect,
Table 1 - Clinical, biochemical, skin and metabolic profile (metabolic syndrome) data related of the one hundred patients with PCO.

\begin{tabular}{lrc}
\hline Variables & \multicolumn{2}{c}{$\mathbf{N}(\%)$} \\
& Mean and standard deviation \\
\hline Age & 25.72 & $( \pm 4.87)$ \\
Menstrual cycle & & $(9 \%)$ \\
$\quad$ Normal & 9 & $(28 \%)$ \\
$\quad$ Oligomenorrhea & 28 & $(63 \%)$ \\
$\quad$ Amenorrhea & 63 & \\
Hirsutism & & $(72 \%)$ \\
$\quad$ Yes & 72 & $(28 \%)$ \\
$\quad$ Not & 28 & $(53 \%)$ \\
Acanthosis nigricans & & $(47 \%)$ \\
$\quad$ Yes & 53 & \\
$\quad$ Not & 47 & $(49 \%)$ \\
Acne & & \\
$\quad$ Yes & 49 & $(51 \%)$ \\
$\quad$ Not & 51 & $(64 \%)$ \\
Metabolic syndrome & & $( \pm 9.31)$ \\
Yes & 36 & $( \pm 18.73)$ \\
$\quad$ Not & 64 & \\
BMI (kg/m2) & 30.63 & \\
AC (cm) & 92.09 &
\end{tabular}

BMI: body mass index; AC: abdominal circumference.

without achieving categorical definitions. With regard to successive diagnostic criteria of MS 6,15-19, based on various groupings of cardiovascular risk factors, one should note

Table 2 - Descriptive data of patients with and without acanthosis nigricans (AN).

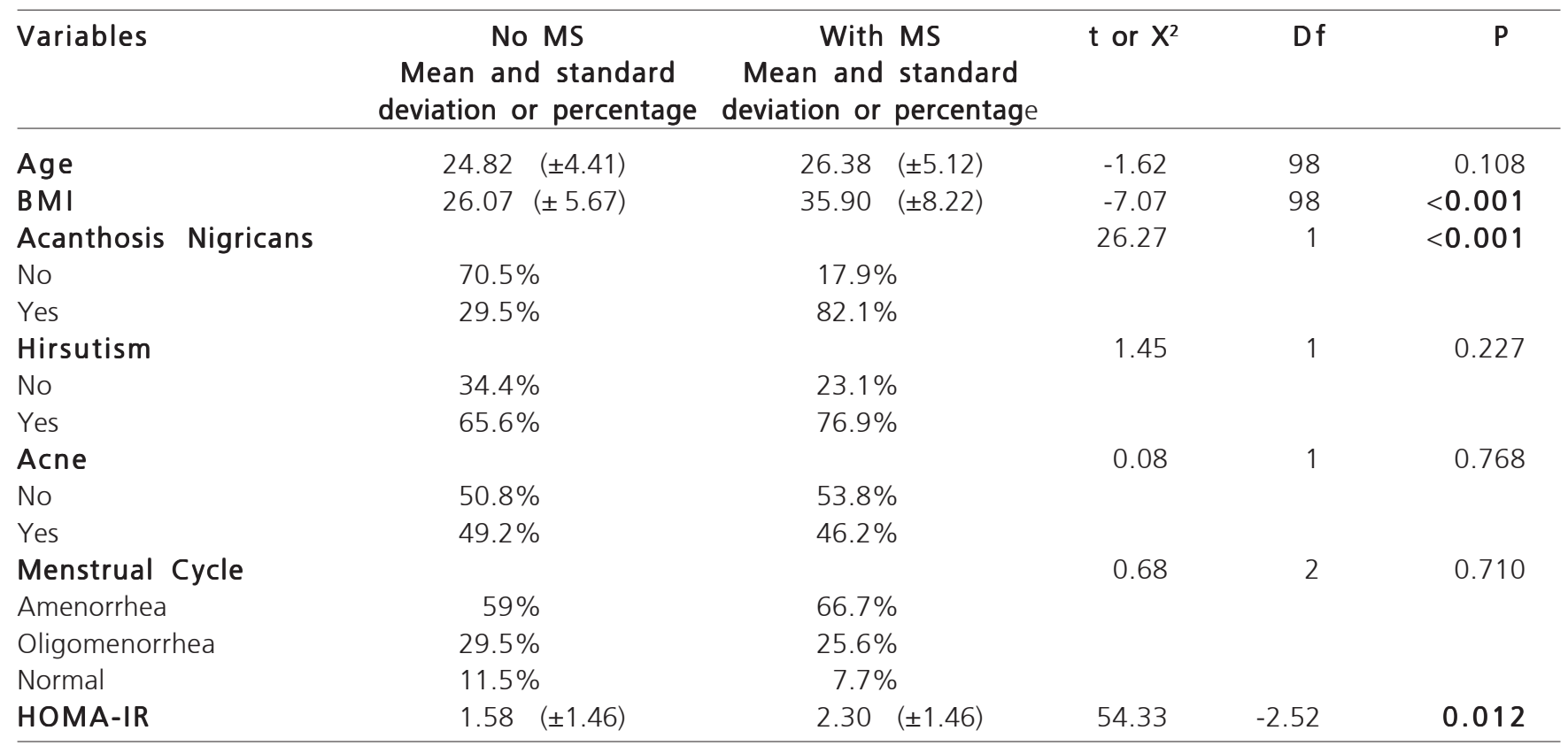

$B M I$ - body mass index. MS - metabolic syndrome.

$p$ - coefficient significance 
the different clinical aspects, as well as the inaccurate necessary adjustments amongst the different components arising, at least in part, from the impaired insulin action and the concomitant compensatory hyperinsulinemia. Furthermore, IR is considered the independent core engine of cardiovascular risk, diabetes being present or not. IR, mostly accompanied by hyperinsulinemia, alters homeostasis and contributes to cardiovascular risk mediated by the coexistence of the metabolic syndrome, which combines the classic stigmata of PCOS. Obesity and visceral fat accumulation tend to be more common when compared to other members of the diagnostic classifications.

We emphasize the autonomy of PCOS as avascular risk factor, especially in relation to type 2 diabetes, distinguishing convergence for diabetes and dyslipidemia regardless of $\mathrm{BMI}^{20}$. Experiments show that the persistence of symptoms related to the syndrome requires systematic research of diabetes despite unchanged fasting glucose. The irrelevance of hyperandrogenism in this scenario has also been observed. Regardless of the clinical manifestations of PCOS tend to wane with advancing age ${ }^{21}$ due to the suppression of menstrual irregularity and hyperandrogenism, there still propensity to diabetes and consequent disorders $20,22,23$. In this context, an increase of 3.3 times has been documented in the increased risk of death from cardiovascular changes or myocardial infarction in postmenopausal women, when that intrinsic PCOS clinical features remain ${ }^{24}$.

The prevalence of type 2 diabetes is increased in about eight times in PCOS patients ${ }^{25}$. And its deleterious effects are not restricted to the cardiovascular risks, with, the development of subclinical atherosclerosis and abnormal echocardiographic parameters, but include, likewise, abnormalities of the immune system, compatible with the low-grade chronic inflammation rendered by $I R^{26}$.

Analysis of this research demonstrates the impact of MS, which likely to be associated with the classical components of PCOS. The prevalence of MS ( $36 \%)$ is similar to previous data 2,27,28, and to the latest 3,29. The significant coexistence with altered HOMA-IR corroborate this physiopathology.

On the other hand, the range of commitments inherent to the pathophysiology of PCOS comprises obesity, type 2 diabetes, and skin manifestations, AN being an important link with insulin resistance. The prevalence of AN, $53 \%$, is noteworthy, sincd its significant association with MS has been described. Furthermore, the incidence of $\mathrm{AN}$ overcame the ones commonly reported ${ }^{30}$, largely predominant over acne.

Despite the MS interaction with PCOS, one must take into account the incipient metabolic dysfunction, as unraveled by the presence of various markers. Thus, the occurrence of anovulation and hyperandrogenism requires concurrent search for components that do not integrate the different clinical risk scores. It is proposed, therefore, irrespective of the age factor, the routine inspection for AN, the visible sign (sometimes subtle), associated with obesity, due to alleged coexistence with the invisible metabolic frame, both inherent to the phenotypic severity of PCOS inflicted in theory by IR.

Thus, there is a need to view PCOS and MS under a new paradigm, one more comprehensive of all features that broaden the scope of the Stein-Leventhal syndrome.

\title{
R E S U M O
}

\begin{abstract}
Objetivo: estabelecer a prevalência da síndrome metabólica (SM) e as respectivas inter-relações clínicas no contexto da síndrome dos ovários policísticos (SOP). Método: estudo transversal, prospectivo, em 100 pacientes portadoras de SOP diagnosticada com base no consenso de Rotterdam (2003). Investigam-se, principalmente, as interrelações da SM, com os dados intrínsecos à SOP. O perfil dermatológico analisado consiste, além da acantose nigricante (AN), na presença de hirsutismo e da acne. O emprego do HOMA-IR (homeostatic model assessment of insulin resistance - modelo matemático de aferição da resistência insulínica) objetivou a correlação com a SM a fim de legitimar a disfunção metabólica com o estado de RI. Resultados: Os valores médios e respectivos desvios-padrões relativos à idade, ao índice de massa corporal e a circunferência abdominal foram respectivamente 25,72 $( \pm 4,87)$, $30,63( \pm 9,31)$ e 92,09 ( $\pm 18,73)$. A prevalência da SM, 36\%, mostrou correlação significativa com o IMC, prevalecido pela constituição do sobrepeso e obesidade, a AN e, em $51 \%$ das pacientes, o estado de resistência à insulina (HOMA-IR). No que concerne ao perfil dérmico, apenas a AN evidenciou correlação significativa com a SM. Conclusão: propõe-se a inspeção rotineira dos componentes metabólicos relacionados ao quadro grave da SOP. Tais parâmetros configuram o risco cardiovascular e tal conduta se constitui de indubitável importância no que tange à saúde pública.
\end{abstract}

Descritores: Síndrome do ovário policístico. Metabolismo. Acantose nigricans. Resistência à insulina. Prevalência.

\section{REFERENCES}

1. Stein IF, Leventhal ML. Amenorrhea associated with bilateral polycystic ovaries. Am J Obstet Gynecol. 1935;29:181-91.
2. Dokras A, Bochner M, Hollinrake E, Sanford M, Vanvoorhis B, Jagasia $\mathrm{DH}$. Screening women with polycystic ovary syndrome for metabolic syndrome. Obstet Gynecol. 2005;106(1):131-7.

3. Wild RA, Carmina E, Diamanti-Kandaris E, Dokras A, EscobarMorreale HF, Futterweit W, et al. Assessment of cardiovascular 
risk and prevention of cardiovascular disease in women with the polycystic ovary syndrome: a consensus statement by the Androgen Excess and Polycystic Ovary Syndrome (AE-PCOS) Society. J Clin Endocrinol Metab. 2010;95(5):2038-49.

4. Akram T, Hasan S, Imran M, Karim A, Arslan M. Association of polycystic ovary syndrome with cardiovascular risk factors. Gynecol Endocrinol. 2010;26(1):47-53.

5. Rotterdam ESHRE/ASRM-Sponsored PCOS Consensus Workshop Group. Revised 2003 consensus on diagnostic criteria and longterm health risks related to polycystic ovary syndrome. Fertil Steril. 2004;81(1):19-25.

6. Grundy SM, Cleeman JI, Daniels SR, Donato KA, Eckel RH, Franklin $B A$, et al. Diagnosis and management of the metabolic syndrome: an American Heart Association/National Heart, Lung, and Blood Institute Scientific Statement. Circulation. 2005;112(17):2735-52.

7. Moura HH, Costa DLM, Bagatin E, Sodré CT, Manela-Azulay M. Polycystic ovary syndrome: a dermatologic approach. An Bras Dermatol. 2011;86(1):111-9.

8. Hatch R, Rosefield RL, Kim MH, Tredway D. Hirsutism: implications, etiology, and management. Am J Obstet Gynecol. 1981;140(7):81530.

9. Slayden SM, Moran C, Sarns WM, Boots LR, Azziz R. Hyperandrogenemia in patients presenting with acne. Fertil Steril. 2001;75(5):889-92.

10. Balen AH, Laven JSE, Tan SL, Dewailly D. Ultrasound assessment of the polycystic ovary: international consensus definitions. Hum Reprod Update. 2003;9(6):505-14.

11. Geloneze B, Vasques ACJ, Stabe CFC, Pareja JC, Rosado LEFPL, Queiroz EC, et al. Índices HOMA1-IR e HOMA2-IR para a identificação de resistência à insulina e síndrome metabólica: Estudo Brasileiro de Síndrome Metabólica (BRAMS). Arq Bras Endocrinol Metab. 2009;53(2):281-7.

12. HOMA Calculator Oxford University. 2004. Available on: http:// www.dtu.ox.ac.uk/homa.

13. Sacks DB, Arnold M, Bakris GL, Bruns DE, Horvath AR, Kirkman $M S$, et al. Guidelines and recommendations for laboratory analysis in the diagnosis and management of diabetes mellitus. Diabetes Care. 2011;34(6):e61-99.

14. Reaven GM. Banting lecture 1988. Role of insulin resistance in human disease. Diabetes. 1988;37(12):1595-607.

15. Alberti KG, Zimmet PZ. Definition, diagnosis and classification of diabetes mellitus and its complications. Part 1: diagnosis and classification of diabetes mellitus provisional report of a WHO consultation. Diabet Med. 1998;15(7):539-53.

16. Einhorn D, Reaven GM, Cobin RH, Ford E, Ganda OP, Handelsman $Y$, et al. American College of Endocrinology position statement on the insulin resistance syndrome. Endocr Pract. 2003;9(3):237-52.

17. Grundy SM, Brewer HB Jr, Cleeman JI, Smith SC Jr, Lenfant C; American Heart Association; National Heart. Lung, and Blood Institute. Definition of metabolic syndrome: Report of the National Heart Lung, and Blood Institute/American Heart Association conference on scientific issues related to definition. Circulation. 2004;109(3):433-8.

18. Alberti KG, Zimmet P, Shaw J; IDF Epidemiology Task Force Consensus Group. The metabolic syndrome-a new worldwide definition. Lancet. 2005;366(9491):1059-62.

19. Alberti KG, Eckel RH, Grundy SM, Zimmet PZ, Cleeman JL, Donato $K A$, et al. Harmonizing the metabolic syndrome: a joint interim statement of the International Diabetes Federation Task Force on Epidemiology and Prevention; National Heart, Lung, and Blood
Institute; American Heart Association; World Heart Federation; International Atherosclerosis Society; and International Association for the Study of Obesity. Circulation. 2009;120(16):1640-5.

20. Wang ET, Calderon-Margalit R, Cedars MI, Daviglus ML, Merkin SS, Schreiner PJ, et al. Polycystic ovary syndrome and risk for longterm diabetes and dyslipidemia. Obstet Gynecol. 2011;117(1):613.

21. Elting MW, Korsen TJ, Rekers-Mombarg LT, Shoemaker J. Women with polycystic ovary syndrome gain regular menstrual cycles when ageing. Hum Reprod. 2000;15(1):24-8.

22. Norman RJ, Dewailly D, Legro RS, Hickey TE. Polycystic ovary syndrome. Lancet. 2007;370(9588):685-97.

23. Chang RJ. Defining risk in women with polycystic ovary syndrome: a need for constant vigilance. Obstet Gynecol. 2011;117(1):1-2.

24. Shaw LI, Bairey Merz CN, Azziz R, Stanczyk FZ, Sopko G, Braunstein $\mathrm{GD}$, et al. Postmenopausal women with a history of irregular menses and elevated androgen measurements at high risk for worsening cardiovascular event-free survival: results from the National Institutes of Health-National Heart, Lung, and Blood Institute sponsored Women's Ischemia Syndrome Evaluation. J Clin Endocrinol Metab. 2008;93(4):1276-84.

25. Apridonidze T, Essah PA, luorno MJ, Nestler JE. Prevalence and characteristics of the metabolic syndrome in women with polycystic ovary syndrome. J Clin Endocrinol Metab. 2005;90(4):1929-35.

26. Tarkun I, Arslan BC, Cantürk Z, Türemen E, Sahin T, Duman C. Endothelial dysfunction in young women with polycystic ovary syndrome: relationship with insulin resistance and low-grade chronic inflammation. J Clin Endocrinol Metab. 2004;89(11):5592-6.

27. Cheung LP, Ma RC, Lam PM, Lok IH, Haines CJ, So WY, et al. Cardiovascular risks and metabolic syndrome in Hong Kong Chinese women with polycystic ovary syndrome. Hum Reprod. 2008;23(6):1431-8.

28. Ehrmann DA, Lijenquist DR, Kasza K, Azzis R, Legro RS, Ghazzi MN; PCOS/Troglitazone Study Group. Prevalence and predictors of the metabolic syndrome in women with polycystic ovary syndrome. J Clin Endocrinol Metab. 2006;91(1):48-53.

29. March WA, Moore VM, Willson KJ, Phillips DI, Norman RJ, Davies MJ. The prevalence of polycystic ovary syndrome in a community sample assessed under contrasting diagnostic criteria. Hum Reprod. 2010;25(2):544-51.

30. Ozdemir S, Ozdemir M, Görkemli H, Kiyici A, Bodur S. Specific dermatologic features of the polycystic ovary syndrome and its association with biochemical markers of the metabolic syndrome and hyperandrogenism. Acta Obstet Gynecol Scand. 2010;89(2):199-204.

Received on 19/11/2012

Accepted for publication 25/01/2013

Conflict of interest: none.

Source of funding: none.

\section{How to cite this article:}

Ávila MAP, Bruno RV, Barbosa FC, Andrade FC, Silva ACO, Nardi AE. Polycystic ovary syndrome: implications of metabolic dysfunction. Rev Col Bras Cir. [periódico na Internet] 2014;41(2). Disponível em URL: http://www.scielo.br/rcbc

Address for correspondence:

Márcio Augusto Pinto de Ávila

E-mail: marcioaavila@terra.com.br 